\title{
The Research on Core Manufacturing Enterprise Delivery Problem on Time
}

\author{
Shi Xinyan \\ School of Economic and Management \\ Shenyang Aerospace University \\ Shenyang, China \\ She Lihong \\ School of Economic and Management \\ Shenyang Aerospace University \\ Shenyang, China \\ e-mail: 1196055162@qq.com
}

\author{
Su Yingying \\ School of Economic and Management \\ Shenyang Aerospace University \\ Shenyang, China \\ e-mail: 2047276131@qq.com \\ Hu Shuchang \\ School of Economic and Management \\ Shenyang Aerospace University \\ Shenyang, China \\ e-mail: 1909858153@qq.com
}

\begin{abstract}
With economic globalization process accelerating, we select the core manufacturing companies' delivery on time for the study is because the core manufacturing enterprises have strong generalizability and typicality, and China is a global manufacturing power that the core manufacturing sector having significant impact on its economic development and overall strength growing. However, the overall level of China's supply chain for manufacturing enterprises is relatively low, the basis for implementing supply chain management is poor, and strategic partnerships between enterprises should also be strengthened, there are many problems for delivery on time. So core manufacturing enterprises delivery on time research is very important for China's economic development.
\end{abstract}

Keywords- Core manufacturing enterprises; Supply chain; Delivery on time; Efficiency.

\section{INTRODUCTION}

We select the core manufacturing companies' delivery on time for the study is because the core manufacturing enterprises have strong generalizability and typicality, and China is a global manufacturing power that the core manufacturing sector having significant impact on its economic development and overall strength growing. However, the overall level of China's supply chain for manufacturing enterprises is relatively low, the basis for implementing supply chain management is poor, and strategic partnerships between enterprises should also be strengthened, there are many problems for delivery on time. In addition, with product life cycles shortened and customer demand for personalization rising, fast response to market demand has become a major direction of supply chain global competition, so core manufacturing enterprises delivery on time research is very important for China's economic development.
Delivery on time reflects the integration, coordination and synchronization of a manufacturing enterprise supply chain management. Punctual delivery of core manufacturing enterprises can effectively shorten response cycle of the whole supply chain, realizing high efficiency of supply chain and reduce operational costs, increase profits, and enhance the competitiveness of enterprises

\section{CURRENT SITUATION OF CORE MANUFACTURING ENTERPRISES' DELIVERY ON TIME}

The economy is ever-changing and market environment is unpredictable, so customers' demand for logistics service quality and service items becomes more and harsher. It is a question how logistics companies meet customers' requirements faster and better. Based on previous exploration of the relationship between logistics supply and demand, the paper proposes three-dimensional network feature of logistics supply and demand, opening up the study on the relationship between logistics supply and demand, providing new methods and ideas to explore the relationship between logistics supply and demand issues from three-dimensional perspective, which has forwardlooking significance for the development of logistics and supply chain management.

With market competition changing, rapid development of information technology, manufacturing industry of developed countries moving, supply chain attracts more and more attentions. Because of the relative concentration of our manufacturing enterprises, the lack of coordination idea between enterprises, so we take further studies for regional collaborative manufacturing supply chain. Regional collaborative manufacturing supply chain development is inseparable from the support of information system. There are two ways realizing regional collaborative manufacturing 
supply chain system: self-built supply chain management platform of core enterprises and supply chain management platform provided by the third-party. Since the core enterprise is a part of the supply chain, the established supply chain management platform is driven by the needs of the core enterprises; therefore, self-built supply chain management platform cannot support all of the supply chain collaboration. Thirdparty provider of supply chain management platform offers an equal opportunity to participate in collaborative activities for the supply chain enterprises.

\section{A. pSupliers lack of overall view and coordination between each other}

To solve this problem, we can build third-party logistics system, which is a useful method and strategy to implement logistics supply chain integration, providing logistics services through coordination of transport and logistics between enterprises, transferring the logistics business to specialized logistics management sector, particularly some special logistics and transport business. By outsourcing to third-party logistics, the enterprises may be able to put time and energy on their core manufacturing business, which greatly improves the efficiency of supply chain management and operations

Third-party logistics system provides an integrated transport template to make small quantity inventory replenishment of supply chain become more economical. But in some cases, small quantity cargo transport is obviously not economical, but the supply chain environment of multi-varieties small quantity production must be small-volume purchase and transport, which increases the supply frequency, and transport frequency will increase transportation cost, obviously uneconomical

\section{B. Logistics system lacking of flexibility and responsiveness and supply chain information transfer uncertainty}

Core manufacturing enterprise production planning and control is not very good for the degree of information sharing. The information mainly refers to the enterprise inside, and the individual information is not centralized. The upstream and downstream of enterprise production are usually single islands of information, without making full use of information resources. But under current competitive environment, this situation is quite dangerous. Enterprises not only need to share internal information, but also share all corporate information resources in the entire supply chain completely. The constraints of each member within the supply chain building partnership: (1) Lack of effective selection method. Therefore, we need to research and choose the evaluation index system of supply chain partners, choose appropriate selection methods and resume evaluation model, which is important to improve the fairness of screening partners, choose favorite supply chain partners and improve the competitiveness of enterprises. (2) Lack of cooperation in new product development. Because the core manufacturing enterprises in supply chain lack of coordination and cooperation in product development, each enterprise is difficult to consider the issue from overall situation, increasing the development and production time, affecting the entire supply chain responding speed to market demands. (3) Lack of risksharing and benefit sharing consciousness. Risk-sharing and benefit sharing is the cornerstone of enterprise supply chain collaboration. The ability to complete risksharing and benefit sharing has direct impact on the quality of cooperation and cooperation period between enterprises. (4) Information communication is not sufficient.

\section{IMPROVEMENT MEASURE OF CORE MANUFACTURING ENTERPRISES DELIVERY ON TIME ISSUES}

\section{A. Complete logistics information system and infrastructure}

In enterprise delivery on time, we must build big data, perform unified management, and then manufacturing can be highly efficient. With the rapid development of information technology, especially cloud computing, networking technology becoming mature, greatly promoting the rise of intelligent logistics industry taking large data applications as a symbol. Intelligent logistics is the goal of logistics development, but large data can support the development of intelligent logistics. The logistics industry and enterprises should make good use of large data, so that it can truly benefit from the transformation.

In the era of big data, intelligence network will enhance the management and control of resources and utilization level, and intelligent process will enhance the management refining and coordination level. One is the control of resources, another is the optimization of workflow; these two things are fundamental problems and core of logistics. Logistics information platform construction and future logistics information platform must base on transit center or dispatch center and clearing house of big data.

To accelerate the integration of road transport, the transport capacities of logistics enterprises are basically composed of three parts: its own vehicles, contract carriers and temporary rental vehicles when there is a large amount of business. In the era of big data in the future, it will go to the platform, based on the capacity for social integration, but integration content generally includes time, space, management, and service.

In the era of big data, transport capacity will also be a platform, but not just a platform, but a large system and a complete ecosystem consisted by many platforms consisting of. And social capacity pool must be in the center of the ecosystem, especially the vehicles have to be fitted GPS now, and GPS operators certainly have a lot of transport capacity customers to customers that so many vehicles together naturally form a social capacity pool. Assuming these proprietary platforms dock with capacity pool, it will naturally produce an integrated platform called capacity integration.

Now, after private platforms docking with public platform, and transport capacity can be gradually 
realized. Once the enterprise private platforms transport capacity resources are full, to make full use of resources, some transport capacity will flow naturally to the society transport capacity pool. So it not only solves the problem of car source authenticity, also solves the problem of supply reliability.

Last kilometer construction in courier industry also plays an important role in enterprises delivery on time. Within the industry, there is such a sentence that the "last kilometer" problem is the culprit of express industry being criticized. For the logistics industry, the last kilometer logistics is the last link of distribution chain; it has the advantage that individual needs are met.

However, in actual conditions, the last kilometer also exists many problems. Besides, due to the rising of county economy, especially some manufacturing enterprises, it will have very important effect for the enterprises to deliver the goods to destination market.

There is great commercial value behind the last one kilometer distribution, so that all enterprises are still coveted to the "last kilometer" logistics services, which is the only way to face customers. The accumulated data in distribution, including the client's tentacles, have the ability to accumulate something of great value based on data procurement and information management, which is very important for front end market forecasts and supply chain management. In order to solve the last kilometer logistics industry challenges, all the relevant parties try to break in a variety of conventional and innovative ideas, to find new solutions.

Therefore, to solve high cost and miscellaneous logistics links issues in logistics industry, a large-scale new logistics company led by the government promoting concept of "joint distribution" comes into being. In them, Beijing joint distribution pilot logistics project "City 100 " is particularly prominent.

The basic idea is that once the goods entering the city, the logistics companies are no longer alone, however, establish a distribution end for the enterprises to perform unified distribution, thus reducing the cost of logistics enterprises. Now for the distribution end, governments subsidize certain amount. Now take "City 100 " for example, outlets are located in universities, community, subway station. Upstream companies cooperate with the courier company, and the courier companies deliver goods to "City 100" outlets, then the personnel here perform "secondary distribution", while integrating the end of resources, it is also positive to solve the submittals complex issues in universities and some high-end community for the courier companies.

In addition to the electricity business, logistics companies and collection companies, convenience stores and other retail outlets are slowly involved initiatively. With those advantages of close to the user, large quantity, high degree of informationization, normative management, convenience stores have been the preferred object of enterprises to develop business.

\section{B. Promote quality of the staff}

Logistics industry staff issues are more prominent. The companies now want to retain people, use good people. So they need to improve the quality of staff. So there must be some regulatory mechanism to achieve standardization model. Sorting violence, theft, service attitude and other issues are subject to be strengthened. Market plays an important role in meeting the daily needs of resident in urban and rural and enriching commodity trading and providing jobs. Some surveys showed that: $66.3 \%$ of consumers preferred to buy fruits and vegetables at markets of agricultural products, $22 \%$ chose the supermarket and another $12.9 \%$ selected the flow individual traders on the street, so it is obvious that markets of agricultural products are still the main place for consumers to buy agricultural products out of habit, convenience and other considerations.

\section{Build supplier supervision and evaluation system}

Due to supplier evaluation and the features of selection purpose, complexity, temporality and risk, the following rules are proposed:

1) Systematic and comprehensive rule: here comprehensiveness means the established index system cannot only reflect the historical achievements and current situation of supplier enterprises, but also indicate the cooperation ability and future development potential of suppliers.

2) Purpose rule: the index system should give objective description of target enterprises' essential feature, structure and components, as well as the relevant elements on with the cooperation is based, and also provide service for evaluation, providing basis for partners' selection.

3) Scientific practicability rule: it refers to the target system can reflect the actual conditions of suppliers scientifically in detail, not only objective but also practical.

4) Qualitative and quantitative rule: when the enterprise evaluate the target enterprise, it is necessary to use both qualitative and quantitative methods, because not all the indexes are qualitative.

5) Expansibility rule: because each industry and enterprise has their special requirements, some special indexes need more people, which needs index system and related evaluation model have expanding space

\section{Pay attention to prevent risks and conduct necessary contract constraint}

Logistics services are the activities taking customer as service target, and expanding a range of logistics process taking products as the center. There are many links in the logistics process, easily occurring a lot of errors like mistake, theft, qualitative change, loss, wrong orders, postponement and other regrettable things, so the logistics industry is a risky business Contractual liability risk of information system contractor, if the contemporary logistics companies want to provide logistics services, they must rely on information technology heavily, not only logistics companies rely on information systems to master and control their goods, services, customers also need to master some dynamics of the goods anywhere and anytime; sometimes such services should be included in the terms of the contract, which should specify the logistics enterprises must promptly provide customers 
with timely and uninterrupted information status of the goods. Logistics enterprises should sign a contract with the provider of information systems to define the responsibility of both parties. Also, it's necessary to know system provider should bear how much responsibility under what circumstances.

Therefore, it necessary to establish integrated logistics system liability insurance, logistics enterprises should take comprehensive measures t to prevent risks, such as: staff training to enhance safety awareness, select and manage partners strictly, and strengthen the overall capacity of logistics enterprise risk prevention measures, etc. However, the logistics service process links load, unexpected factors are immeasurable, so strengthening management can reduce human risk, but no problem is absolutely impossible.

In comprehensive logistics liability insurance, it is now not only limited to logistics service providers, but also should include all aspects of the logistics, the insured may be many. They may be logistics companies, personnel, transportation companies. All of these units can be insured separately or as a subcontractor of logistics companies, included in the logistics company insurance policies

\section{CONCLUSION}

Core manufacturing enterprises' delivery on time is filled with attractive profit and broad market. Ensuring the punctuality of delivery has been generally considered to be another profit source for manufacturing companies to reduce material consumption, improve labor productivity. In today's world with rapid development of science and technology, especially after China's accession to WTO, the domestic core manufacturing enterprises are facing important issues like mechanism change, efficiency improvement and enhancing corporate background competitiveness. There is no delay to ask management for efficiency and improve the management level.

The overall level of China's core manufacturing enterprises is not very high, and the supply and demand information is difficult to obtain accurately, with a certain degree of subjectivity in improvement measures. In reality, if the core manufacturing enterprises need to ensure the punctuality of delivery, they must rely on their own production conditions and the external objective conditions, to consider more factors. Hope to have the opportunity to discuss referring real core manufacturing enterprises' supply conditions.

\section{REFERENCES}

[1] Luo Feng Research on Regional Manufacturing Supply Chain System Based on Collaborative Product Commerce. [D] Xiamen University .2012.4

[2] Cao Wenqin, Xu Bing, Zhu Haiyan Supply Chain Integration Research Based on Core Manufacturing Enterprises. [D].2009.6 East China Jiaotong University, School of Mechanical and Electrical Engineering, JMC, Ltd. Logistics Department

[3] Chen Jianhua, Ma Shihua Supply Chain Logistics Integration Mode Based on Supply Hub [J]. National Natural Science Foundation Funding Key Projects.2011.8

[4] Ding Jingzhi, Ju Songdong. Dimensional Network Features of Logistics Supply And Demand [J]. School of Economics and Management, Beijing Jiaotong University .2012.10

[5] Yang Xiaomin, Jia Pingren. Supply Chain Node Enterprises Cooperation Management and Innovation [J]. Jiangsu Joint Vocational and Technical College .2012.10.

[6] Zhang Dehai. Research on Logistics Service Supply Chain Coordination Mechanism [C]. University of Electronic Science and Technology Graduation Thesis Set .2010.9

[7] Yan Xiaoying. Analysis on Building the Core Competitiveness of Manufacturing Supply Chain [J]. Public Business .2009.9

[8] Ge Lan. Research on Manufacturing Supply Chain Reliability Diagnostic Methods. [D]Management Science and Engineering .2011.9

[9] Chen Huoquan. Enterprise Logistics Information Strategy Research Based on Dynamic Equilibrium [D]. Huaqiao University .2012.3

[10] Guan Xu, Ma Shihua, Ying Danfeng. Research on Assembly System Delivery on Time Model Based on Inventory Balancing Strategies [D]. Wuhan University, School of Economics and Management .2013.8

[11] Li Yan. The Development of Foreign Reverse Logistics and Its Implications to China [J]. World Forum, 2012, (4): 116-117.

[12] Wang Daqin, Zhang Lihua, Jiang Liang. Research on Manufacturing Enterprise Reverse Logistics Operation Mode Selection Method [J]. Shanghai Management Science .2012, (3): $85-88$

[13] Zong Gang, Zhao Hongtao. The Role of Manufacturing Enterprises to Implement Reverse Logistics and Problems to Be Solved [J] Market Modernization 2011, (25): 111-111.

[14] FENG Yi-xiong, ZHENG Bing, TAN Jianrong.National.Exploratory study of logistics service quality scale based .Natural Science Foundation.2012.8

[15] A. Kiisler.The Third Party Logistics Supplier Selection and Evaluation.Journal of Software .2012.7

[16] Heiko Gebauer,Gunther Kucza ,Chunzhi Wang.Spare parts logistics for the Chinese market.An International Journal.2011.11 